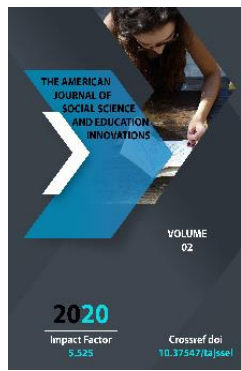

Copyright: Original content from this work may be used under the terms of the creative commons attributes 4.0 licence.

\section{Shaping Mathematical Thinking Skills In Primary Schools}

Durdona Toshpulatova Komiljanovna, Lecturers Of Tashkent State Pedagogical University Named After Nizamiy, Uzbekistan

Turdali Sultonov Muhtarovich

Lecturers Of Tashkent State Pedagogical University Named After Nizamiy, Uzbekistan

\title{
ABSTRACT
}

The arithmetic material forms the main content of the course. The core of the elementary course consists of arithmetic of natural numbers and basic quantities. In addition, the basic concepts of geometry and algebra are combined in this course.

\section{KEYWORDS}

Mathematics, Arithmetic, Propaedeutics, Concentrates, Theory, Practice, Mathematical Methods.

\section{INTRODUCTION}

In primary school, math is an integral part of school math. Basic math taught in grades 1-2 and age-appropriate elemental concepts are given. The upper classes are taught in an expanded, deepened, and enriched way. So, the content of elementary mathematics also determines the content of higher mathematics. 


\section{MATERIALS AND METHODS}

The structure of elementary mathematics has its own characteristics:

1. Arithmetic material is the main content of the lesson. It is taught in combination with arithmetic material without being taught in the form of basic sections of natural number arithmetic, basic quantities, algebra and geometric propagative courses.

2. Elementary material is concentric. For example, decimal numbering is taught first, followed by numbering and arithmetic operations. Then you learn how to do arithmetic in the first place, and then you do arithmetic in the next.

These include numeracy, quantities, fractions, algebraic and geometric materials.

3. Theoretical and practical issues are interconnected.

4. Mathematical concepts, properties, legal connections are carried out in the course of interdependence.

5. The developed state of each concept is explained.

For example, before learning arithmetic operations, the essence of the operation is revealed, then the properties of the operation, the relationship between the next components, then the result of the operation, and finally the relationship between the operations.

6. Basic concepts are given in relation to the basic concepts.

For example, multiplication is based on addition.

In elementary school, mathematics is divided into arithmetic, algebraic, and geometric material.

In the formation of mathematical thinking in the primary school, the teacher has the following goals: general education, educational purpose, practical purpose. These goals are interdependent and complementary.

1. The teacher is required to:

a) To provide students with a system of mathematical knowledge, knowledge, and skills;

b) Study of real mathematical methods;

c) Ensuring that students' oral and written skills are developed and developed;

d) To provide students with such knowledge in mathematics as to develop knowledge, skills and abilities through knowledge, active learning activities.

2. Educational purpose. Math teaching requires students to be persistent, diligent, thorough and able to express their opinions and conclusions, especially through observation, and the fluency of the ideas on which they are based. Symbols are used in mathematics to represent the relationship between quantities. The teacher's job is to teach you how to translate mathematical ideas into symbolic language. We need to cultivate a sense of self-awareness, independence and contentment. Teaching math teaches students to concentrate.

The teacher should:

a. The student is able to understand the connections in the material world, the changes in quantities, the interrelationships;

b) Encourage students to take an active interest in learning mathematics;

c) Attitudes towards labor, patriotism and aesthetic taste; 
d) Education in the history of the Uzbek nation, including the history of mathematics education;

e) To develop students' thinking and mathematical skills;

3. Practical purpose. The purpose of teaching mathematics is to teach students how to apply what they have learned. To teach students to apply the acquired knowledge to numbers and mathematical expressions, the operations on points and to use them in solving various problems are the main goals. It's about teaching people how to apply their knowledge to everyday life.

\section{RESULTS AND DISCUSSIONS}

In practice, teachers often say that one method of assignment is simpler or more complex than another. Furthermore, no matter how artistically didactic materials are, no matter how productive and in-depth they may be in their content, they will not be able to solve all the methodological tasks quickly, because no teacher can teach the machine.

Thus, didactic materials should be considered as one of the ways to control the level of students' mastery of educational materials. However, a certain course may not be the best for the teacher. For this reason, didactic materials do not preclude the teacher from creating controls for individual examinations that allow students to determine their level of knowledge. This is one of the main tasks of general methodology.

It depends on the level of preparation for the development of mathematical thinking in the implementation of the educational tasks, which are the main task of teaching mathematics in grades 1-4.
Therefore, the task is to determine the knowledge of the first graders, to equalize the knowledge of the students, that is, to transfer the knowledge of students with low education to those who can improve it. The teacher counts the students' knowledge in a special notebook in the following order:

1. How long can you count?

2. How many numbers can be added?

3. How many numbers can be divided?

4. Can you use the symbols $>,<,=$ ?

5. Can I add and subtract unknowns?

6. What are the names of the figures?

7. How many can be written?

8. Can you distinguish right, left, less, more, heavy, light, peers?

9. Can money, price, hour, minute, length, weight be measured?

The main methods of teaching children should be the development of skills in the analysis, synthesis, comparison, generalization, stratification and other operations. This will help the students to develop their oral and written skills and increase their interest in learning mathematics.

\section{CONCLUSION}

In conclusion, we can mention that the arithmetic material forms are the main content of the course as the core of the elementary course consists of arithmetic of natural numbers and basic quantities and the basic concepts of geometry and algebra in secondary schools.

\section{REFERENCES}

1. Jumaev M.E, Tadjiyeva Z.G'. Methods of teaching mathematics in primary school. (Textbook for OY.) Tashkent. "Science and Technology" 2005. 
2. Jumaev M. E, Practicum on methods of teaching mathematics in primary school. (For HOME) Tashkent. "Teacher" 2004

3. Jumaev M.E. First grade mathematics textbook.) Tashkent. "Yellow", 2005, p.48

4. Axmedov M. .AbduraxmonovaN.Jumaev M.E. Methodical manual of first grade mathematics.) Tashkent. Sharqr, 2005

5. Bikbaeva N.U, R.I.Sidelnikova, G.A.Adambekova. Methods of teaching mathematics in primary school. (Methodical manual for primary school teachers.) Tashkent. "Teacher" 1996

6. Bikboeva.N.U. YangiboevaE.Ya. Second grade math textbook. Tashkent. "Teacher" 2005

7. Bikboeva.N.U, Yangiboeva E.Ya. Third grade math textbook. Tashkent. "Teacher" 2005

8. Toshpulatova, D. (2019). РОЛЬ МЕНТАЛЬНОЙ АРИФМЕТИКИ В ПОВЫШЕНИИ МАТЕМАТИЧЕСКОЙ ГРАМОТНОСТИ В НАЧАЛЬНОЙ ШКОЛЕ. Theoretical \& Applied Science, (12), 184186.

9. Sarimsakova, D. (2019). Communicative competence as a result of EF teaching and learning ISJ Theoretical \& Applied Science, 12 (80), 166-169 https://dx. doi. org/10.15863. In TAS (Vol. 80).

10. Muhamadjonovna, S. D. (2020). The key concepts of forming sociolinguistic competence of future English language specialists. Asian Journal of Multidimensional Research (AJMR), 9(5), 118-121.

11. Muhamadjonovna, S. D. (2020). The development of sociolinguistic competence of future English language teachers through computer technologies.

12. Sarimsakova, D., \& Rashidova, S. (2017). DEVELOPING INTERCULTURAL COMPETENCES WITH CASE STUDIES. In
WORLD SCIENCE: PROBLEMS AND INNOVATIONS (pp. 212-214). 